\title{
Analisis Semiotika Pierce pada Pertunjukan Tari Dhânggâ Madura
}

\author{
Ulfa Sufiya Rahmah ${ }^{1}$, Sujinah Sujinah ${ }^{2}$, Ali Nuke Affandy ${ }^{3}$ \\ ${ }_{1,2,3}^{3}$ Pascasarjana, Universitas Muhammadiyah, Surabaya, \\ ${ }^{1}$ ulfasr38@gmail.com \\ ${ }^{2}$ sujinah@pps.um-surabaya.ac.id * \\ 3 alinukeaffandy@yahoo.com \\ * Corresponding author
}

Diterima: 22 Oktober 2020

Direview: 12 Desember 2020

Diterbitkan: 31 Desember 2020

Hak Cipta @ 2020 oleh Penulis (dkk) dan Jurnal Sosial Humaniora (JSH)

*This work is licensed under the Creative

Commons Attribution International License (CC

BY 4.0).

http://creativecommons.org/licenses/by/4.0/

Open Access

\begin{abstract}
Subject Area: Cultural Study
Abstract

Dhengge dance embodies the description of fishermen's activities that have a sense of beauty that is caused by movement and music produced by the mouth. Human life cannot be separated from signs, and signs always have a load of meaning. The symbols contained in this dance were analyzed qualitatively by Pierce's semiotics. The costumes of the dancers are interpreted by the fishermen as having a firm attitude and a fighting spirit in facing life, steadfast and tough. Freedom, openness, simplicity, courage, manliness, and persistence are among the cultural ethos of the Madurese people. The dance movement depicts a trip to go to sea, search for fish to return to the beach, which means that life can be likened to running a boat into the middle of the ocean which at times is hit by big waves and strong winds, the boat to lose control, lose direction and even sink. For that we need planning, hard work, togetherness, a sense of brotherhood and require patience, confidence, persistence, and surrender.
\end{abstract}

Keywords: dhânggâ' dance; costumes; movements; semiotics; symbols.

\section{Latar Belakang}

Tari merupakan objek karya seni yang menarik untuk dikaji dengan berbagai pendekatan penelitian maupun sudut pandang. Penanganan budaya harus dimulai dari daerah sebagai inti budaya bangsa, karena daerah tersebut yang memahami budayanya (Sujinah et al., 2020). Kabupaten Pamekasan terdiri atas 13 kecamatan, salah satunya kecamatan Pademawu, tempat munculnya pertunjukan tari Dhânggâ. Nama Tari Dhânggâ' berasal dari sebuah akronim Madura (kèrata bhâsa) yaitu Atangdhâng Magâgâ' (menari dengan gagah). Tari Dhânggâ' menggambarkan tentang proses bernelayan persiapan awal, mendorong perahu kelaut, mendayung sekaligus mengendalikan ke tempat tujuan, majâng (menangkap ikan dengan payang/sejenis jaring) sampai akhirnya menuju pantai kembali. Tari tersebut dilakukan oleh 9 (sembilan)/10 (sepuluh) orang penari dengan menggunakan perahu mainan dan 8 (delapan) buah dayung yang dipegang oleh masing masing penarinya, dengan posisi 1 (satu) orang di depan sebagai pemimpin, dan 4 orang di kanan perahu dan 4 orang di kiri perahu. Musik Dhânggâ' menggunakan suara mulut sebagai irama dengan memadukan 5 (lima) macam komposisi sesuai dengan komposisi tariannya. Musik tersebut dimainkan oleh masing masing penarinya. Dengan demikian seorang penari Dhânggâ' sekaligus sebagai pemusiknya (Wawancara Zainollah Pewaris Tari Dhânggâ Madura 2020). 
Tari merupakan wujud ekspresi estetis yang ditemukan pada masyarakat-masyarakat pra-moderen. Tari dijumpai pada masyarakat terpencil yang tingkat kebudayaannya sangat sederhana. Tetapi, tari juga dijumpai pada masyarakat-masyarakat modern, masyarakat yang sadar teknologi, dan pada masyarakat metropolitan (Alkaf, 2012). Tari dapat diasumsikan sebagai salah satu bentuk perilaku ekspresif manusia dan suatu kegiatan yang memiliki daya tarik tradisi (Aleksandrovich, 2016).

James Danandjadja menyampaikan bahwa di balik foklor (tarian) terdapat makna yang ingin disampaikan sebagai bentuk wejangan kepada generasi penerus (Danandjaja, 1991) Hal ini perlu dibaca secara mendalam menggunakan teori semiotik, agar menemukan makna tersirat di balik elemen-elemen tarian tersebut sehingga memudahkan generasi penerus memahami dan mewarisi makna tarian. Penelitian tentang pertunjukan seni sudah banyak dilakukan baik di Indonesia dan maupun di negara-negara lain di dunia. Kepedulian untuk meneliti pertunjukan seni dilakukan oleh Sangye Dondhup yakni pertunjukan seni Tibet, walau rumit banyak factor penentu namun tetap dilakukan, peneliti ingin menemukan peluang dan tantangan dalam penelitian seni pertunjukan Tibet (Dondhup, 2017).

Penelitian sejenis dilakukan Umbar yang meneliti seni Bantengan Malang dengan kajian semiotik. Dalam penelitiannya disimpulkan bahwa beberapa simbol yang ada dalam kesenian Bantengan di Malang merupakan bentuk dari realitas rakyat untuk mengusir penjajah (Umbar, 2018). Realitas yang digambarkan dengan topeng bermacam-macam binatang seperti banteng, macan, dan kera memberikan pengetahuan tentang watak-watak golongan yang ada saat penjajahan. Penelitian tentang seni tari juga dilakukan Fitriani yaitu pertunjukan tari Tarek Pukat dari Aceh. Simpulan yang diperoleh dalam penelitian Tarek Pukat bahwa simbol atau tanda yang disampaikan manusia dalam komunikasi memiliki makna-makna khusus, sehingga terjadi interaksi. Tarek Pukat menggambarkan interaksi antar sesama anggota masyarakat pesisir Aceh yang saling bekerja sama dalam berkegiatan membuat pukat dan menarik pukat sehingga terjalin komunikasi. Melalui Tarek Pukat masyarakat berpotensi memiliki pengetahuan proses pembuatan pukat yang menjadi alat untuk mata pencaharian masyarakat Aceh pesisir (Fitriani, 2017).

Penelitian dengan objek tari juga dilakukan oleh Alkaf yaitu tari rakyat Boyolali dan disimpulkan bahwa eksistensi tari tidak terbatas pada ruang, waktu, geografis maupun sekat-sekat sosial budaya. Tari bisa ditemukan di semua kalangan baik pelosok dengan peradaban yang sangat sederhana sampai perkotaan (di beberapa hotel berbintang, restoran berkelas, upacara resmi pemerintah, bahkan perguruan tinggi). Tari juga mempunayi hubungan yang kuat dengan sosial dan budaya tempat tari itu lahir, bertahan, hingga metamorfosis dan memiliki relasi erat dengan keagamaan (Alkaf, 2012). Selanjutnya penelitian pertunjukan tari juga dilakukan oleh Khutniah terkait tari Kridha Jati Jepara. Penelitian dilakukan untuk mendeskripsikan upaya menjadikan tari Kridha sebagai bagian bahan ajar wajib di sanggar Hayu Budaya, serta menggelar pementasan dengan fokus pada kualitas garap, tidak menolak saat diundang pentas, bekerja sama dengan dinas pariwisata, melakukan pementasan pada upacara penting (penyambutan tamu), dan regenerasi (Khutniah, 2013).

Tentang eksistensi seni tari tradisional dan kaitannya dengan pembentukan karakter anak diteliti oleh Retnoningsih yang menyatakan bahwa terdapat nilai Pendidikan pada seni tari (Retnoningsih, 2017). Sedangkan eksistensi seni pertunjukan tradisional Kuda Lumping di daerah Tanjung Morawa telah 
mengalami pergeseran (Pasaribu, 2015). Tari ini sebelumnya diselenggarakan dalam acara tahunan bersih desa dan menyambut Muharam-an, namun sekarang berubah menjadi pertunjukan pada acara keluarga seperti ulang tahun dan arisan sehingga hanya sekadar untuk hiburan. Walau demikian, tari ini harus tetap dilestarikan karena dapat menjadi asset budaya dan asset wisata. Hal ini berbeda dengan penelitian Pangestu dkk menemukan bahwa tari Lang Nginang dari suku Dayak Mualang Kabupaten Belitang Kalimantan berfungsi sebagai sarana komunikasi dengan roh nenek moyang, sarana untuk memengaruhi kekuatan alam, terutama yang berkaitan dengan keselamatan pangayau, serta sarana untuk melegitimasi tradisi dalam upacara pangayau (Pangestu \& Kuswarsantyo, 2020). Hal senada ditemukan (Medilianasari \& Retnowati, 2020) bahwa seni pertunjukan tari tidak hanya semata hiburan karena mengandung nilai estetika, namun juga ada nilai ritual (upacara yang mengandung mitos). Hal ini dibuktikan dalam penelitiannya terhadap tari Rampak Yakso dari Dieng Jawa Tengah, bahwa tari ini berperan secara ritual yaitu sebagai pengaman dalam upacara pemotongan rambut gimbal yang dilakukan oleh masyarakat Dieng setahun sekali. Selain itu tari ini juga melambangkan kepahlawanan yang tampak jelas dari gerakan tari dan kostum yang digunakan.

Hal senada dirasakan oleh Akas yang meneliti tari Nkwanwite di Nigeria yang prihatin terhadap perlakuan tari tradisional yang kurang mendapatkan intrepretasi, sampai-sampai peneliti menyarankan agar sarjana nontari juga menghargai dan mengapresiasi penggunaan simbol-simbol dalam tari sebagai alat komunikasi, karena di dalamnya mengandung nilai-nilai pendidikan. Koreografi tidak hanya sebagai alat peraga namun juga perlu diinterpretasikan nilai-nilai yang dikandungnya. Simbol dalam tari harus dilestarikan sehingga tari tidak hanya dilihat secara harfiah/artefak budaya semata, namun simbol-simbol itu harus diinterpretasikan untuk memahami esensi sosial budaya (NicholasC \& Prisca I, 2020).

Tari mengandung simbol atau tanda yang dibalut makna yang dikontruksi melalui konvensi sosial (Silva, 2020). Simbol atau tanda yang ditunjukkan manusia dalam berinteraksi memiliki makna tertentu, sehingga terjadilah komunikasi (Fitriani, 2017). Seringkali kontruksi sosial dipandu oleh kekuatan ideologis yang berusaha untuk naturalisasi tanda. Dalam penelitian Silva menemukan bahwa dalam pemaknaan tari Kathak dari India tidak lepas dari gagasan pribadi penciptanya, namun juga dibentuk oleh ide-ide yang mendominasi, sosial, budaya, dan politik yang ada.

Koentjaraningrat mengutarakan, nilai budaya merupakan konsep hidup yang muncul, serta tumbuh di pemikiran manusia, diyakini karena keagungan nilainya, dijadikan referensi dalam berkehidupan, sehingga masyarakat dipengaruhi budaya tersebut. Menurut Kluckohn terdapat lima persoalan budaya dalam kehidupan masyarakat, yaitu hakikat hidup, hakikat dari hubungan manusia dengan sesama manusia, hakikat karya manusia, hakikat kedudukan manusia, hakikat hubungan manusia dengan alam sekitar (Suluh et al., 2018).

Penelitian-penelitian tersebut menunjukkan bahwa tradisi lisan dan semiotik memiliki keterkaitan sehingga layak dijadikan kajian mendalam, sebab tradisi lisan bukan hanya karya seni, tetapi juga sebagai pedoman nilai yang mengatur kehidupan sosial penikmatnya. Sebagai produk budaya, tari dapat menjadi objek bagi kajian semiotik. Fenomena dan noumena masyarakat dalam 
kaitannya dengan tarilah yang mnjadi wilayah penelitian. Sayangnya tari Dhânggâ' belum tersentuh oleh civitas akademica. Hal itulah yang menjadi titik mula studi ini.

Penelitian terdahulu tersebut juga menginspirasi penulis untuk menganalisis pertunjukan tari Dhânggâ yang hampir punah agar memiliki dokumentasi dan upaya regenerasi dan pelestarian budaya. Sebagian besar generasi muda di Madura tidak tertarik karena merasa tidak paham dengan maksud dan tujuan tari Dhânggâ (Wawancara Zainollah Pewaris Tari Dhânggâ Madura 2020) Hal ini akan memberi koneksi, kekuatan, dan ketahanan generasi penerus terhadap alam dan masyarakatnya. Namun kekhawatiran akan lenyapnya kebudayaan pesisir ini sempat disampaikan oleh Zainollah (pewaris pertunjukan tari Dhânggâ). Zainollah menyatakan bahwa sudah terbukti banyaknya karya budaya Indonesia yang pindah tangan ke negara lain. Kekhawatiran Zainolllah bertambah saat didatangi beberapa orang asing untuk mengambil gambar dan merekam gerakan tarinya (Syahid \& Farhan, 2017). Alasan-alasan tersebut menjadikan penelitian ini menjadi penting untuk dipublikasikan.

Penelitian ini sebagai salah satu usaha pelestarian budaya khususnya kesenian. Pertunjukan Tari Dhânggâ' menjadi suatu warisan kebudayaan masyarakat Madura yang sudah hampir punah, sehingga diharapkan dengan adanya penelitian ini, masyarakat Madura pada umumnya lebih mengetahui dan lebih melestarikannya untuk anak cucu selanjutnya. Berdasarkan latar belakang tersebut, maka pada kesempatan ini penelitian difokuskan pada pendeskripsian kostum dan gerakan yang terdapat dalam "Pertunjukan Tari Dhânggấ'. Melalui kostum yang digunakan dan gerakan-gerakan dalam tarian, pembaca akan mendapatkan informasi makna yang tersirat dalam simbol-simbol tersebut.

\section{Tinjauan Pustaka}

Pierce menganggap bahwa semiotika bisa diaplikasikan pada segala variasi tanda dan salah satu bidang ilmu tidak dianggap lebih penting dari yang lain (Pierce, 1966). Tanda adalah sesuatu yang menjadi wakil sesuatu yang lain dalam batas yang ditentukan. Tanda-tanda mengajak kita berpikir, berkomunikasi, dan memaknai semua yang ditampilkan oleh alam manusia. Pemaknaan dalam tanda tersebut digunakan untuk membaca simbol dan gerak pada keseluruhan pertunjukan tari Dhânggâ. Semiotik ala Pierce ini cocok untuk menganalisis pertunjukan Dhânggâ karena memiliki analisis trikotomi.

Pierce memiliki tiga klasifikasi tanda yang disebut dengan trikotomi, yakni ikon, indeks, dan simbol. Ikon adalah tanda yang memiliki kemiripan "rupa" (resemblance) dan dikenali oleh pemakainya. Indeks adalah tanda di antara representamen dan objeknya yang memiliki keterkaitan dengan fenomenal atau eksistensial (Pierce, 1991) Sedangkan simbol adalah tanda yang konvensional dan arbitrer. Trikotomi ini berguna untuk menganalisis elemen-elemen dalam pertunjukan tari Dhânggâ, mulai dari kostum, gerak dan ekspresi, dan pertunjukan tari yang menjadi fokus permasalahan karya tulis ini.

Semiotik ala Pierce ini akan membantu melalui hubungan triadic atau segitiga semiotika yang juga disebut dengan pendekatan semiotik triadik (tiga elemen dasar), yaitu representasi [tanda $=\mathrm{T}$; sesuatu], objek [O = sesuatu dalam kognisi manusia], dan interpretasi [ $\mathrm{I}=$ proses penafsiran]. Selanjutnya Pierce menyatakan bahwa titik sentral kajian semiotiknya adalah trikotomi relasi "menggantikan" di antara tanda 
[representamen] dan objeknya melalui interpretan. Representamen [T] adalah sesuatu yang dapat ditangkap secara pancaindra manusia [perceptible]. Kehadiran tanda tersebut mampu membangkitkan interpretan [I] sebagai suatu tanda lain yang ekuivalen dengannya dalam pikiran seseorang [interpreter]. Penafsiran makna oleh pemakai tanda terpenuhi ketika representamen telah dikaitkan dengan objek. Sedangkan objek [O] yang diacu oleh tanda merupakan sebuah konsep yang dikenal oleh pemakai tanda sebagai "realitas" atau apa saja yang (dianggap) ada (Winfried, 2006). Skema semiotic triadic [tiga elemen dasar] tersebut sebagai berikut.

Gambar 1. Bentuk Hubungan Ketiga Konsep Triadik ( Eco, 2015; Umberto, 2015)

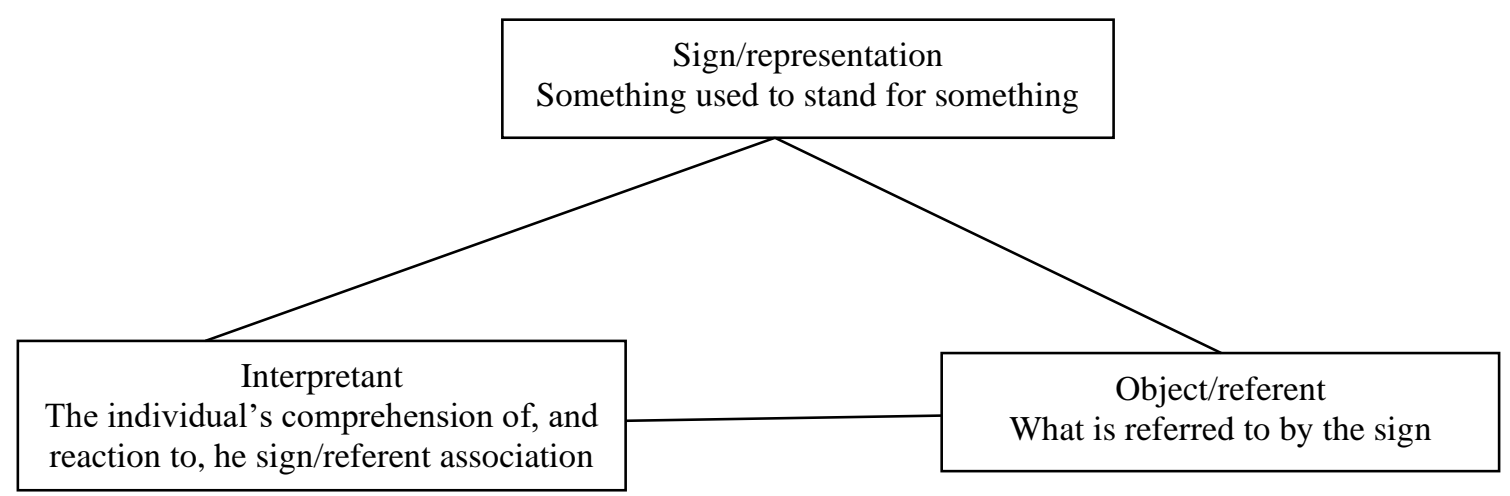

Konsep triadic memunculkan proses semiosis (proses triadic) dan hubungan tidak pernah putus, yaitu interpretan akan berkembang menjadi representemen dan seterusnya. Elemen-elemen pertunjukan akan dibagi ke dalam tiga triadik kemudian dimaknai dan diinterpretasikan dengan makna di luar objek, sebagaimana Pierce menjelaskan bahwa interpretant merupakan apa yang diproduksi tanda dan di pikiranlah yang menjadi penginterpretasinya dan juga dapat dipahami sebagai representemen. Sehingga terjadi proses perkembangan dalam interpretasi yang tidak berkesudahan sesuai dengan perkembangan kurun waktu yang ada (Eco, 2015).

\section{Metode Penelitian}

Penelitian Pertunjukan seni Dhânggâ ini menggunakan pendekatan kualitatif yang disajikan secara deskriptif dan interpretatif. Kostum yang digunakan dalam pertunjukan seni Dhânggâ dianalisis dengan menggunakan pendekatan semiotika. Pendekatan kualitatif membutuhkan kekuatan analisis yang lebih mendalam, terinci, namun luas dan holistic, maka kekuatan akal adalah satu-satunya sumber kemampuan analisisdalam seluruh proses penelitian (Bungin, 2011). Dengan pendekatan kualitatif peneliti dapat mendeskripsikan makna simbol yang terkandung dalam pertunjukan tari Dhengge' Madura. Penelitian ini dilakukan di desa Malangan Kecamatan Pademawu, Kabupaten Pamekasan, tempat pertunjukan tari ini lahir.

Data dikumpulkan dengan menggunakan metode dokumentasi dan wawancara. Wawancara dilakukan kepada Zainollah selaku pewaris pertunjukan tari Dhengge" Madura. Wawancara dilakukan selama 5 kali yakni tgl 28 Februari 2020, 9 Maret 2020, 1 April 2020, 14 Agustus 2020, dan 8 Oktober 2020. Sedangkan 
dokumentasi yang dikumpulkan merupakan dokumen milik Zainollah selaku pewaris pertunjukan tari Dhengge' Madura. Data yang terkumpul dialihwahanakan menjadi sebuah naskah pertunjukan seni Dhengge" selanjutnya naskah tersebut dianalisis dengan menggunakan teori trikotomi (tanda, objek, dan interpretan) Charles Sanders Peirce dan teori Michael Foucault.

\section{Hasil Penelitian dan Pembahasan}

\section{Gambaran Umum Pertunjukan Tari Dhânggâ}

Pertunjukan Tari Dhânggâ adalah sebuah pertunjukan yang tidak dikenal penciptanya dan tidak diketahui pula tahun berdirinya. Yang pasti tari itu sampai sekarang oleh masyarakat (Malangan Pademawu Timur) dianggap tari turun temurun, dan dianggap/diakui sebagai tari tradisional (Wawancara Zainollah Pewaris Tari Dhânggâ Madura 2020).

Tari Dhânggâ merupakan salah satu kebudayaan Madura yang berasal dari Malangan Kecamatan Pademawu, Kabupaten Pamekasan. Nama tari ini merupakan akronim dari bahasa Madura Atangdhâng Magâgâa' (dhang dan ge) yang memiliki arti "menari dengan gagah". (Wawancara Zainollah Pewaris Tari Dhânggâ. Madura 2020). Pertunjukan tari ini yang merupakan pengejawatahan kehidupan masyarakat Pademawu yang secara geografis terletak di pesisir pantai. Seperti layaknya masyarakat Indonesia yang tinggal di pesisir pantai, mayoritas mata pencaharian penduduknya sebagai nelayan.

Daerah Pademawu Timur berbatasan langsung dengan laut (pesisir). Berposisi di pesisir, sehingga mata pencaharian penduduk pada umumnya sebagai nelayan. Perilaku para nelayan pada waktu bernelayan (majâng) menghasilkan kesenian Tari Dhânggấ' ini. Perilaku ini bermula dari salah satu anggota nelayan berkidung (ngèjhung) sementara anggota yang lain mengiringi dengan musik mulut. Perilaku yang akhirnya menjadi kebiasaan ini muncul karena (1) untuk hiburan dan menghilangkan rasa lelah disela-sela bekerja; (2) belum ada alat musik/tidak memungkinkan untuk membawa alat musik pada saat bernelayan karena perahu yang ditumpangi sangat kecil, (3) musik akapela merupakan musik praktis yang berasal dari suara mulut, dan menghasilkan harmoni yang indah untuk dinikmati (Wawancara Zainollah Pewaris Tari Dhânggâ Madura 2020).

Perilaku tersebut menjadi kebiasaan para nelayan di Pademawu Timur. Yang pada akhirnya kebiasaan itu dilakukan pula di darat guna dipertontonkan pada masyarakat di kampung ketika mempunyai hajatan. Biasanya pertunjukan Tari Dhânggâ' sebagai penyegar/selingan ketika pagelaran macapat sudah berlangsung cukup lama sehingga para anggota macapat yang sedianya sudah kecapekan maka akan segar kembali bahkan berkeringat dan merasa senang karena ikut terlibat dalam pertunjukan prosesi bernelayan (Tari Dhânggâ') (Wawancara Zainollah Pewaris Tari Dhânggâ. Madura 2020).

Tari Dhânggâ menggambarkan kehidupan nelayan mulai dari proses persiapan awal melaut, mendorong perahu ke laut, mendayung sekaligus mengendalikan ke tempat tujuan dan majâng (menangkap ikan dengan payang/sejenis jaring) sampai akhirnya menuju pantai kembali. Tari ini dimainkan oleh sembilan sampai sepuluh penari. Properti diperlukan berupa perahu mainan dan delapan buah dayung. Dayung tersebut dipegang oleh masing masing penarinya. Posisi para penari, yakni satu orang di depan yang berfungsi sebagai 
pimpinan, empat orang di kanan perahu dan empat orang di kiri perahu yang masing-masing bertugas antara lain mendayung/menjalankan perahu menuju ke laut dan menuju ke pantai (Dokumen Zainollah Pewaris Tari Dhânggâ).

Musik Dhânggâ' menggunakan suara mulut sebagai irama dengan memadukan 5 (lima) macam komposisi sesuai dengan komposisi tariannya. Musik tersebut dimainkan oleh masing masing penarinya, sehingga seorang penari Dhânggâ' sekaligus sebagai pemusiknya. Tari Dhânggấ' memiliki 5 komposisi yang dipraktikan dalam setiap pementasan. Komposisi tersebut memiliki makna di setiap masing-masing komposisi, sehingga penonton tidak hanya melihat sebuah pertunjukan hiburan, melainkan bisa mengambil makna pada kostum sebagai warisan budaya serta makna pada setiap gerakan tarinya. (Dokumen Zainollah Pewaris Tari Dhânggâ)

Berikut paparan tanda (T), Objek (O), dan Interpreter (I) yang terhadap pada kostum Pertunjukan Tari Dhânggâ' dan gerakan pada Pertunjukan Tari Dhânggâ' Pademawu Pamekasan Madura. Setelah diidentifikasikan berdasarkan metode triadic Pierce, selanjutnya dianalisis dengan menggunakan teori Faucault.

Makna Kostum Pertunjukan Tari Dhânggâ'

Tabel 1. Penafsiran Kostum Tari Dhânggấ' semiotika Charles Sander Pierce

\begin{tabular}{|c|c|c|c|}
\hline No & Tanda $(\mathrm{T})$ & Objek $(\mathrm{O})$ & Interpreter (I) \\
\hline \multirow[t]{4}{*}{1} & Udeng & Udheng (udeng) & $\begin{array}{l}\text { Udheng atau ikat kepala } \\
\text { bagi masyarakat Madura } \\
\text { memiliki arti simbolis baik } \\
\text { dari ukuran, motif, dan cara } \\
\text { pemakaian. }\end{array}$ \\
\hline & Jarik & jarik & $\begin{array}{l}\text { Jarik ini biasanya dililitkan } \\
\text { di bagian perut lalu } \\
\text { dikalungkan di leher }\end{array}$ \\
\hline & Celana gombor hitam & $\begin{array}{l}\text { Kaos oblong corak } \\
\text { belang-belang merah } \\
\text { putih }\end{array}$ & $\begin{array}{l}\text { Kaos oblong dengan corak } \\
\text { belang-belang dengan } \\
\text { warna merah putih tersebut } \\
\text { sangat kental dengan } \\
\text { budaya masyarakat } \\
\text { Madura. Motif garis } \\
\text { dengan warna tegas } \\
\text { tersebut memperlihatkan } \\
\text { sikap tegas serta semangat } \\
\text { juang masyarakat Madura } \\
\text { dalam menghadapi } \\
\text { kehidupan. }\end{array}$ \\
\hline & & $\begin{array}{l}\text { Celana gombor } \\
\text { warna hitam }\end{array}$ & $\begin{array}{l}\text { Model celana gombor atau } \\
\text { longgar melambangkan sifat } \\
\text { kebebasan dan keterbukaan } \\
\text { orang Madura. }\end{array}$ \\
\hline
\end{tabular}




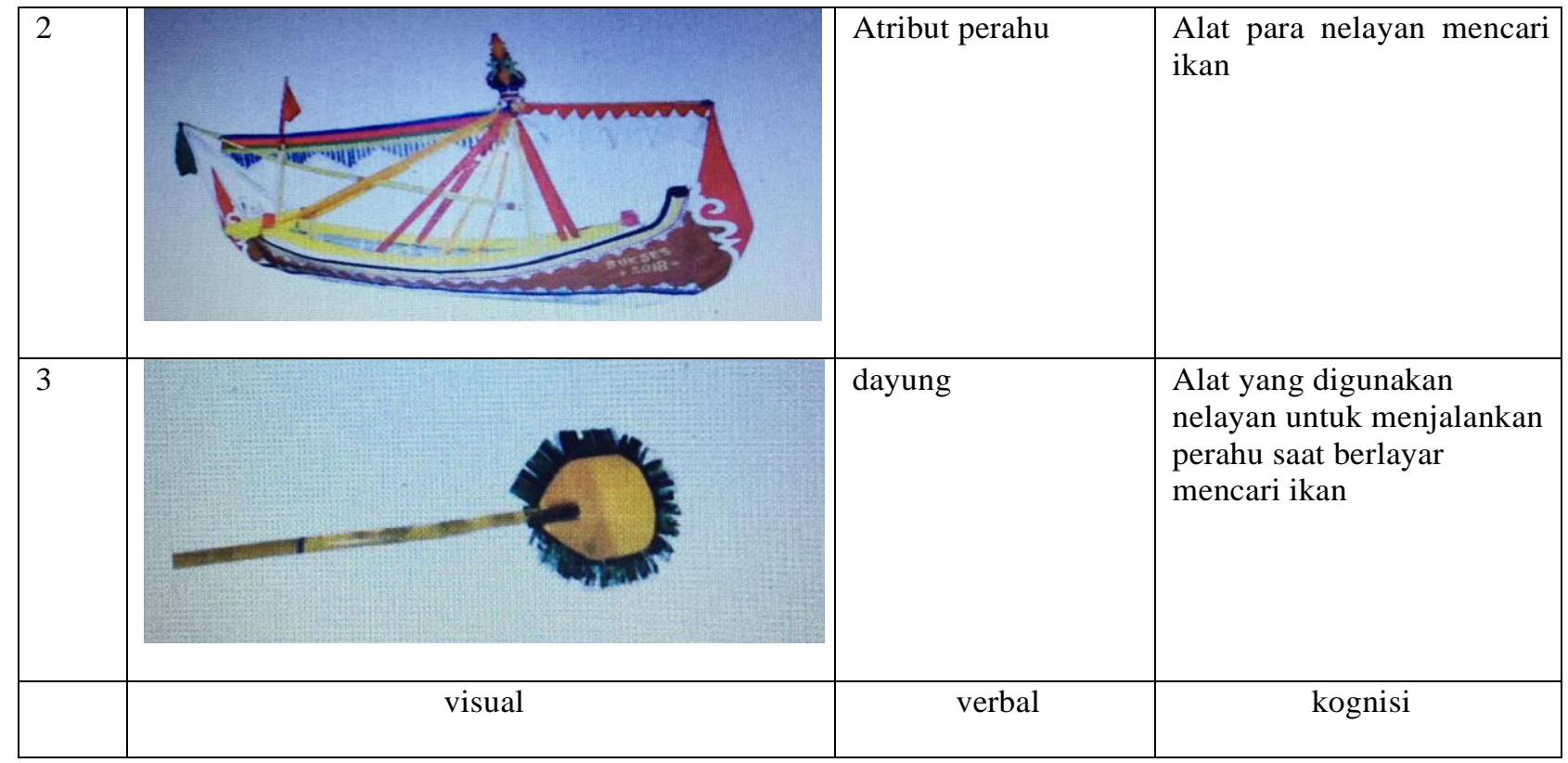

Sumber: dokumen milik Zainollah Pewaris Tari Dhânggâ Madura

Pertunjukan seni Dhânggâ' merupakan seni yang ditontonkan tentang prosesi bernelayan, sehingga tata rias tidak terlalu diperhatikan. Untuk memunculkan karakter tertentu seperti protagonist atau antagonis, tata rias khusus kurang diperhatikan dalam pertunjukan tari Dhânggâ' ini. Semua penari memunyai kedudukan yang sama yakni memeragakan peran sebagai nelayan. Jika penari berhias (make up), hal ini hanya digunakan agar penari tidak tampak kusam saat pentas (bukan untuk memunculkan karakter tertentu). Sebaliknya kostum (tata busana) sangat mendapat perhatian pada pertunjukan tari Dhânggấ' ini.

Kostum yang digunakan merupakan pakaian adat Madura yang sering dipakai masyarakat Madura dalam kehidupan sehari-hari. Pakaian tersebut dikenal masyarakat Madura sebagai pakaian "sakera" (salah seorang ksatria yang berasal dari Madura). Kaos oblong dengan corak merah putih yang dilengkapi dengan gombor (komprang) warna hitam, odheng (udeng), dan jarik yang dililitkan di bagian perut kemudian dikalungkan di leher.

Kostum tari dhengge ini sangat kental dengan budaya masyarakat Madura. Kostum tersebut pada umumnya dipakai pelaku seni dari berbagai yang berasal dari Madura, tidak terkecuali dalam pertunjukan seni tari dhengge Pademamu Pamekasan Madura ini. Pakaian ini merupakan pakaian yang sudah biasa dipakai oleh masyarakat Madura dalam kehidupan sehari-hari. Pakaian ini adalah pengaruh cara berpakaian pelaut dari Eropa, terutama kaos bergaris yang digunakan.

Udeng atau ikat kepala banyak jenis dan ukuran. Ukuran odheng tongkosan membuat si pemakai harus sedikit mendongak ke atas karena lebih kecil dari kepala, bermakna "meskipun sangat berat beban tugas yang dipikul hendaknya diterima dengan lapang dada”. Bentuk dan cara memakai odheng juga menunjukkan derajat kebangsawanan seseorang. Semakin tegak kelopak odheng tongkosan, semakin tinggi derajat kebangsawanan. Semakin miring kelopaknya, maka derajat kebangsawanan semakin rendah. Ada versi menyebut iket (odheng) telah ada dalam legenda Aji Saka, pencipta tahun Saka atau tahun Jawa, sekitar 20 abad yang lalu. Diceritakan Aji Saka berhasil mengalahkan Dewata Cengkar dalam peperangan hanya dengan 
menggelar kain penutup kepala yang kemudian dapat menutupi seluruh tanah Jawa. Versi lain menyatakan iket merupakan pengaruh budaya Hindu dan Islam. Para pedagang dari Gujarat keturunan Arab selalu mengenakan sorban, kain panjang yang kemudian dililitkan di kepala, lalu orang Jawa terinspirasi memakai ikat kepala serupa mereka. Ada pula versi yang mengatakan, di satu waktu akibat peperangan kain menjadi barang yang sulit didapat sehingga petinggi keraton meminta seniman untuk menciptakan ikat kepala yang lebih efisien yaitu udeng (Adie, n.d.).

Celana gombor warna hitam sebagai bentuk keberanian. Masyarakat Madura memiliki etos budaya, salah satunya sikap gagah dan pantang mundur sebagai bentuk keberanian. Kesederhanaan bentuk celana ini pun menunjukkan kesederhanaan masyarakatnya. Gaya bicara Suku Madura terkenal blak-blakan, selain itu mereka dikenal hemat, disiplin, dan rajin bekerja keras (abhantal omba' asapo' angen). Dalam kehidupan masyarakat Madura harga diri sangat penting, terlihat dari falsafah: katembheng pote mata, angok pote tolang (Mengenal Pandangan Hidup Orang Madura, 2012).

Pertunjukan Tari Dhânggâ' ini ditunjang dengan properti berupa perahu dan dayung. Perahu dan dayung merupakan peralatan atau sarana yang wajib ada ketika seseorang akan melaut atau bernelayan. Kadang-kadang dalam konteks tertentu properti ini dihiasi agar lebih menarik, misalnya dengan menghias perahu tiruan dengan kertas dan pita yang berwarna-warni sehingga tampak lebih meriah dan indah dipandang mata. Dayung pun dihiasi dengan kertas dan dibuat semenarik-menariknya (wawancara dengan Zainollah Pewaris Tari Dhânggâ Madura 2020).

Berdasarkan analisis semiotik Pierce, ditemukan bahwa atribut tari Dhânggâ merupakan identitas masyarakat Madura yang ingin disampaikan pada khalayak dengan tujuan menandai eksistensi mereka. Bagi masyarakat Madura penting untuk dinilai eksis, melalui kesenianlah mereka mengokohkan eksistensinya (Foucault, 1972). Identitas pada atribut tari inilah yang menjadikan mereka akan mudah diidentifikasi saat berbaur dengan suku budaya yang lain.

\section{Makna Gerakan Pertunjukan Tari Dhânggâ'}

Tabel 2. Penafsiran Gerakan Tari Dhânggấ' semiotika Charles Sander Pierce

\begin{tabular}{|c|c|c|l|}
\hline No & Tanda (T) & Objek (O) & \multicolumn{1}{c|}{ Interpreter (I) } \\
\hline 1 & gerakan pembuka & $\begin{array}{l}\text { Gerakan pembuka dilakukan } \\
\text { oleh pemimpin tari. Tari } \\
\text { tersebut mengambarkan } \\
\text { pemeriksaan persiapan sebelum } \\
\text { melaut. Pemeriksaan tersebut } \\
\text { dilakukan terhadap kondisi } \\
\text { perahu, perlengkapan perahu } \\
\text { dan kelengkapan anggotanya. }\end{array}$ \\
\hline
\end{tabular}




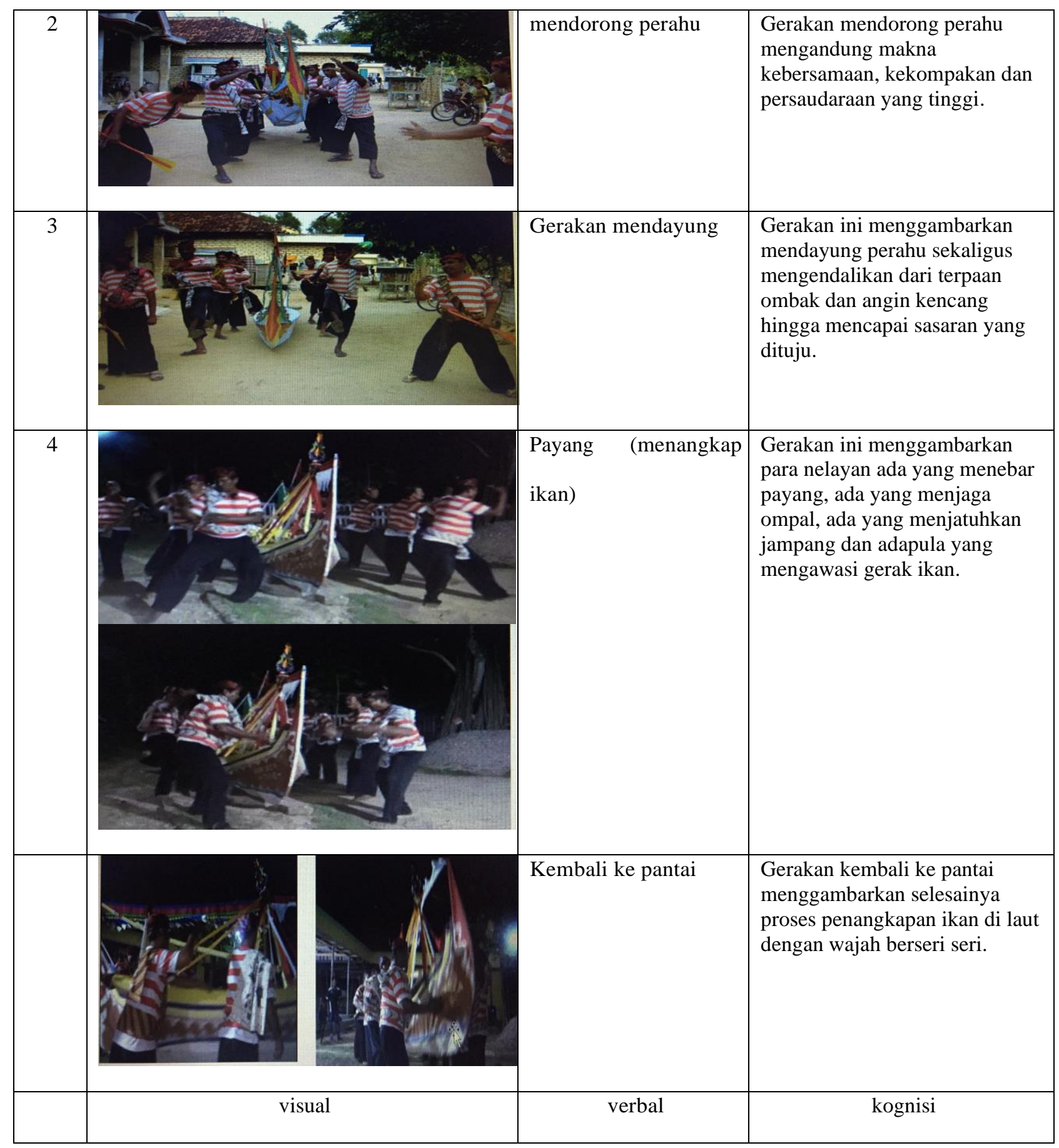

Sumber: dokumen milik Zainollah Pewaris Tari Dhânggâ Madura

Berdasarkan hasil pengumpulan data pertunjukan seni Dhânggâ' dianalisis sebagai berikut. Gerakan pembuka menggambarkan perlu seorang pemimpin dalam sebuah komunitas, termasuk dalam bernelayan atau melaut. Gerakan pemimpin menggambarkan pemeriksaan persiapan sebelum melaut. Pemeriksaan tersebut dilakukan terhadap kondisi perahu, perlengkapan perahu dan kelengkapan anggotanya. Makna yang bisa dipelajari dari simbol tersebut adalah bahwa segala aktivitas akan terlaksana dengan baik jika dipersiapkan dengan baik dan direncanakan secara matang.

Gerakan selanjutnya adalah mendorong perahu secara bersama-sama. Hal ini menggambarkan pentingnya kebersamaan, kekompakan, dan persaudaraan yang perlu dijunjung tinggi dalam mencapai 
tujuan. Sehingga apabila terjadi permasalahan yang berat atau sesulit apa pun akan dapat diatasi dengan baik. Begitu juga dalam bernelayan kebersamaan, kekompakan, dan merasa satu saudara merupakan bekal utama yang harus dimiliki oleh para nelayan. Kita tidak bisa membayangkan kalau masing-masing nelayan punya keinginan sendiri-sendiri di tengah laut yang jauh dari daratan. Juga diibaratkan sebuah rumah tangga, kalau semua anggota keluarga menjadi pengendali, apa jadinya. Tentunya akan sulit mencapai tujuan.

Gerakan mendayung perahu untuk mencapai tempat yang dituju oleh para nelayan. Mendayung juga menggambarkan pengendalian dari terpaan ombak dan angin kencang yang selalu menghinggapi para nelayan di tengah laut. Dalam menjalankan roda kehidupan diperlukan kegigihan, kesabaran, dan perjuangan sehingga setiap segala permasalahan yang kadang-kadang datang tidak terduga, dapat terselesaikan dengan baik.

Gerakan selanjutnya adalah gerakan menangkap ikan. Pada gerakan ini tampak para nelayan melaksanakan amanah yang sudah diberikan kepada masing-masing. Ada nelayan yang bertugas menebar jaring (alat menangkap ikan yang terbuat dari benang tertentu), ada yang bertugas menjaga ompal (pelampung bagian ujung), ada yang bertugas menjatuhkan jampang (jangkar kayu), da nada yang bertugas mengawasi gerak atau jalannya ikan. Tersirat makna bahwa sebuah pekerjaan harus dikerjakan sesuai dengan keahlian atau kemampuan masing-masing. Kalau tidak atau kalau dipaksakan pastinya hasilnya tidak optimal.

Gerakan terakhir adalah gerakan kembali ke pantai. Gerakan ini menggambarkan selesainya kegiatan melaut atau penangkapan ikan di laut. Hal ini ditunjukkan dengan wajah yang berseri-seri, bahagia dan bersyukur karena sudah berhasil mendapatkan tangkapan ikan. Tangkapan ikan untuk menghidupi keluarganya sebagai bentuk pertanggungjawaban seorang suami bagi istri dan bapak bagi anak-anaknya. Wajah gembira, hilang kekhawatiran dan rasa capek selama mengarungi lautan yang tertinggal adalah kebagiaan. Kebahagiaan yang dicapai merupakan buah perjuangan yang luar biasa yang dihadapinya. Setelah kesulitan akan datang kemudahan. Seperti tercantum pada Al-qur'an surat Al-Insyirah ayat 5-6 yang artinya "karena sesungguhnya sesudah kesulitan itu ada kemudahan. Sesungguhnya sesudah kesulitan itu ada kemudahan.”

Tari Dhânggâ' memiliki filosofi sebuah kehidupan dapat diibaratkan menjalankan sebuah perahu ke tengah samudra yang sewaktu waktu diterpa ombak besar dan angin yang begitu kencang sehingga memungkinkan perahu tersebut lepas kendali, kehilangan arah dan tujuan bahkan bisa tenggelam dibawa deras arus laut. Untuk mengatasinya memerlukan perencanaan, kerja keras, kebersamaan, rasa persaudaraan serta memerlukan kesabaran, percaya diri, kegigihan dan tawakkal.

Berdasarkan analisis semiotik Pierce gerak tari Dhânggâ menunjukkan bahwa masyarakat Madura merupakan masyarakat pekerja keras, agamis dan menjadikan laut sebagai bagian hidup. Analisis triadik pada gerak tari menggambarkan bahwa Madura identik dengan pekerjaan sebagai nelayan karena hidup berdampingan dengan laut secara geografis, sehingga masyarakat diajak untuk bersahabat dengan kondisi laut melalui tarian ini. Selanjutnya, gotong royong menjadi bagian penting dalam berkelompok di Madura, bagi mereka di mana pun berada sesama manusia harus kompak dan kerja sama agar berhasil mencapai tujuan bersama. Gerak dalam tari ini menunjukkan identitas dan kekuatan masyarakat Madura, yaitu ulet dan 
tawakkal. Hal tersebut menjadi salah satu alasan masyarakat Madura dianggap mudah memiliki teritorial (daerah kekuasaan) meskipun berada di wilayah luar Madura. Misalnya di Surabaya terdapat beberapa wilayah terutama Surabaya bagian utara menjadi dominasi penduduknya berasal dari Madura (orang Madura), misalnya daerah Kapasan dan sekitarnya.

\section{Kesimpulan}

Simbol pada kostum yang digunakan oleh penari pertunjukan tari Dhânggâ' diintepretasikan bahwa para nelayan memiliki sikap tegas serta semangat juang dalam menghadapi kehidupan, teguh dan keras (kaos belang putih dan merah). Berdasarkan analisis semiotik Pierce, ditemukan bahwa atribut tari Dhânggâ merupakan identitas masyarakat Madura yang ingin disampaikan pada khalayak dengan tujuan menandai eksistensi mereka. Masyarakat Madura penting untuk dinilai eksis, melalui kesenianlah mereka mengokohkan eksistensinya. Berdasarkan analisis Pierce gerak tari Dhânggâ menunjukkan bahwa masyarakat Madura merupakan masyarakat pekerja keras, agamis dan menjadikan laut sebagai bagian hidup. Gerak dalam tari ini menunjukkan identitas dan kekuatan masyarakat Madura, yaitu ulet dan tawakkal. Itulah mengapa mereka dianggap mudah memiliki teritorial (daerah kekuasaan) meskipun berada di wilayah selain Madura.

\section{Ucapan Terima Kasih}

Pada kesempatan ini, kami menyampaikan terima kasih kepada DRPM Kemenristek/BRIN yang telah mendanai penelitian ini melalui skema penelitian tesis magister tahun pendanaan 2020 dengan SK Nomor 083/SP2H/LT/DRPM/2020. Ucapan terima kasih juga penulis sampaikan kepada Pak Zainollah selaku pewaris seni pertunjukan tari Dhengge' atas bantuannya dan dukungannya selama penelitian ini berlangsung.

\section{Referensi}

Adie. (n.d.). Odheng, ikat kepala khas Madura. https://adiethonet.wordpress.com/odheng-ikat-kepala-khasmadura/

Aleksandrovich, M. (2016). Psychology of Dance: Barthes ' Ideas and Semiotics of Dance. EUROPEAN HUMANITIES STUDIES: State and Society Maria, 4-19.

Alkaf, M. (2012). Tari sebagai gejala kebudayaan: studi tentang eksistensi tari rakyat di boyolali. Komunitas, $4(2), 125-138$.

Bangsawan, A., \& Juwariyah, A. (2020). The Representation of Javanese Culture in the "Knight Kris" Animated Movie: Charles Sanders Pierce's Semiotic Analysis. 380(SoSHEC), 258-261. https://doi.org/10.2991/soshec-19.2019.57

Basit, A. (2017). Health communication in the Quran: Charles Saunders Pierce's semiotic analysis. Jurnal Komunikasi: Malaysian Journal of Communication, 33(4), 76-88. https://doi.org/10.17576/JKMJC2017-3304-05 
Bungin, B. (2011). Penelitian Kualitatif. Prenada Media Group.

Danandjaja, J. (1991). Folklor Indonesia: Ilmu Gosip, Dongeng, dll. Garviti Press.

Dondhup, S. (2017). Looking Back at Tibetan Performing Arts Research by Tibetans in the People's Republic of China: Advocating for an Anthropological Approach. Revue d'Etudes Tibétaines, 40, 103125.

Eco, U. (2015). Teori Semiotika: Signifikansi, Komunikasi, Teori Kode, Serta Teori Produksi Tanda. Kreasi Wacana.

Fitriani, F. (2017). Nelayan sebagai ide penciptaan tari. Imaji, 15(2), 179-188.

Foucault, M. (1972). The Archeology of Knowledge. Routledge.

Khutniah, N. (2013). Upaya mempertahankan eksistensi tari kridha jati di sanggar hayu budaya kelurahan pengkol kecamatan jepara kabupaten jepara.

Medilianasari, R., \& Retnowati, T. H. (2020). Role of Rampak Yakso Dance in Cutting Dreadlocks Ritual Ceremony in Dieng Banjarnegara Central Java. 444(Icaae 2019), 246-249.

Mengenal Pandangan Hidup Orang Madura. (2012). Lontar Madura. https://www.lontarmadura.com/mengenal-pandangan-hidup-orang-madura/3/

NicholasC, A., \& Prisca I, O. (2020). SIGNIFYING SYMBOLS IN TRADITIONAL DANCE:A STUDY OF NKWANWITE DANCE Akas, Nicholas C. PhD 1 and Okeke Prisca I. 2 1, 2. AJELLS, 7(1), 1-20.

Pangestu, H., \& Kuswarsantyo. (2020). Functions of Lang Nginang Ritual Dance in Mengayau Traditional Rite in Belitang. ICAAE 2019, 444(Icaae 2019), 49-53.

Pasaribu, P. (2015). ANTHROPOS: Jurnal Antropologi Sosial dan Budaya Eksistensi Seni Pertunjukan Tradisional Kuda Lumping di Desa Bangun Rejo Kecamatan Tanjung Morawa. 1(1).

Pierce, C. S. (1966). Colecteed Papers of C.S. Pierce (Cambridge (Ed.); 7th ed.).

Pierce, C. S. (1991). Peirce on Signs: Writings on Semiotic by Charles Sanders Peirce (J. Hoopes (Ed.)). Unversity of Carolina Press.

Retnoningsih, A. D. (2017). EKSISTENSI KONSEP SENI TARI TRADISIONAL TERHADAP PEBENTUKAN KARAKTER SISWA SEKOLAH DASAR. 7(1), 20-29.

Silva, W. T. N. De. (2020). Meaning Making in Kathak Dance: A Semiotic Analysis of Two Kathak Dance Performances . Jounal OfInformation and Computational Science, 10(3), 389-393.

Sujinah, Wardhono, A., \& Yunianti, S. (2020). Localism and Cultural Preservation Policy in Indonesia: Ideas and Challenges. 436, 25-31. https://doi.org/10.2991/assehr.k.200529.006

Suluh, D., Dewi, K., Hilman, Y. A., Muhammadiyah, U., \& Muhammadiyah, U. (2018). Pelestarian W ayang "Krucil” dan Kekuatan P olitik. 11.

Syahid, \& Farhan. (2017). Mengenal Tari Dhangga', Budaya Madura dari Pamekasan.

Umbar, K. (2018). Kajian semiotika c.s. pierce dalam kesen. IKADBUDIV, September.

Umberto, E. (2015). Teori Semiotika Signifikansi Komunikasi, Teori Kode, serta Teori Produksi Tanda. Kreasi Wacana.

Winfried, N. (2006). Semiotika. Airlangga University Press. 